\title{
MAPEAMENTO TEMPORAL DA ÁREA URBANA DO MUNICÍPIO DE FERREIRA GOMES-AP POR IMAGENS LANDSAT
}

\author{
Rosiney dos Santos Ferreira ${ }^{(a) ;}$ Renata dos $\operatorname{Santos}^{(\mathrm{b})}$ \\ (a) Departamento de Filosofia e Ciências Humanas,Universidade Federal do Amapá, rosiney.ferreira@bol.com.br \\ (b) Departamento de Filosofia e Ciências Humanas, Universidade Federal do Amapá, renataunifap@gmail.com
}

\section{Eixo: GEOTECNOLOGIAS E MODELAGEM ESPACIAL EM GEOGRAFIA FISICA}

\section{Resumo}

\begin{abstract}
O trabalho apresentado consistiu em analisar o uso e ocupação da área urbana de Ferreira Gomes$\mathrm{AP}$, por meio de imagens de satélite Landsat, atribuindo às perspectivas de planejamento urbano para a referida área. Através do geoprocessamento, ferramenta bastante requisita. Sendo utilizada para a classificação supervisionada em três imagens de anos distintos. Onde foi analisada as alterações principalmente no de 2015 , ano pós-instalação de empreendimentos hidrelétrico no município.
\end{abstract}

Palavras chave: Geoprocessamento, uso da terra, planejamento.

\section{Introdução}

O processo de crescimento das áreas urbanas nos países emergentes possui uma dinâmica própria, marcadas por inadequações estruturais, que influenciam fatalmente na qualidade de vida da população. O reflexo da falta de planejamento territorial é apresentado de vários modos, como, por exemplo, através da utilização de áreas potencialmente interessantes para determinado empreendimento (turismo, área de proteção agricultura) invadidas pela expansão urbana sem planejamento (Silva \& Tavares 2004).

Existe diferentes formas de extração de informações provenientes dos produtos de Sensoriamento Remoto, a classificação da cobertura e uso da terra é uma importante técnica de identificação de feições naturais e/ou antrópicas, que possibilita compreender suas dinâmicas na superfície terrestre. Os resultados podem variar de acordo com a metodologia de classificação empregada. Ao mensurar as quantidades dos elementos puros que formam o pixel misturado é possível gerar imagens de frações de vegetação, sombra e solo (PONZONI et al, 2012). Nesse eixo temático que essa pesquisa tenta contribuir, através da análise espacial do geoprocessamento aplicada de um possível planejamento urbano no estudo de caso do município de Ferreira Gomes município do Amapá.

O trabalho se baseia na premissa de que com as possíveis expansões urbanas no município de Ferreira Gomes vem se expandido, e com isso o aceleramento do processo de degradação ambiental. Fato que pode estar ocorrendo devido a ação antrópica (devido ao aumento da população e a área urbana), que faz uso e ocupação da terra de forma inapropriada. Por meio de analise espacial, com auxílio das 


\section{OS DESAFIOS DA GEOGRAFIA FÍSICA NA FRONTEIRA DO CONHECIMENTO Instituto de Geociências - Unicamp \\ Campinas - SP \\ 28 de Junho à 02 de Julho de 2017}

geotecnologias na elaboração do mapeamento, usando a técnica de classificação e identificação de áreas naturais e antrópicas, podendo assim atribuir caracterização as mudanças na paisagem e possibilitando as perspectivas no âmbito de planejamento para a área.

O objetivo do trabalho é analisar o uso e ocupação da área urbana de Ferreira Gomes-AP, por meio de imagens de satélite Landsat, atribuindo às perspectivas de planejamento urbano para a referida área. Identificar através de classificação supervisionada a possível expansão da área urbana e possíveis evoluções antrópicas dos ambientes naturais, no que se destaca a vegetação com três anos distintos e quatro mapas.

\section{Materiais e Métodos}

\section{1 Área de estudo}

A cidade de Ferreira Gomes localiza-se no estado do Amapá, nas coordenadas geográficas lat. $00^{\circ}$ 51'17 “N e long. 51¹0'25” W, com população média de 6.901 habitantes, segundo o IBGE (2015). Segundo Ferreira Gomes (2013), a cidade está dividida em dois bairros e duas ocupações, a saber; bairro Centro, bairro Montanha, ocupação Ameixal e ocupação Portelinha, FIG. 1.

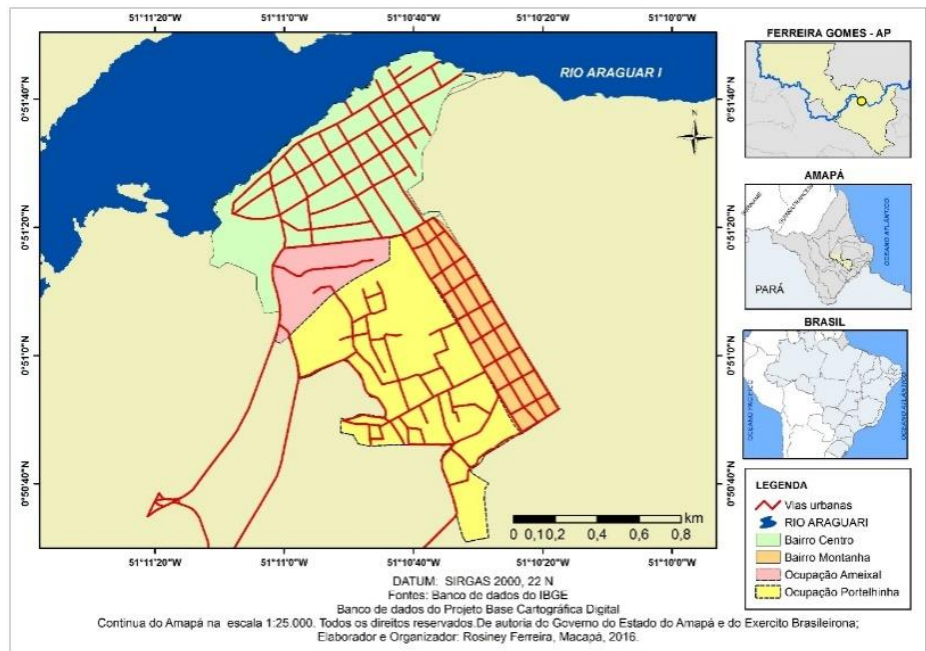

Figura 2- Àrea de estudo localizado no município de Ferreira Gomes-AP.

O processo de urbanização em Ferreira Gomes tem ocorrido de maneira rápida, com crescimento populacional de 65,5\% para a última década (2000 a 2010) com média de 21 habitantes por hectares para a área total do munícipio (IBGE, 2010).

\subsection{Metodologia}

As etapas metodológicas se dividem em três : Pré-Geoprocessamento (organização e aquisição dos dados), Geoprocessamento (escala, configurações das legendas dos mapas e definições das classificações e analise ambiental dos dados) e Pós-Geoprocessamento. Em seguida será apresentada em detalhes a metodologia. 
Fase 1- Pré-geoprocessamento dos dados

Investigação, organização de materiais e aquisição dos dados.

Nessa fase foi executado um levantamento para o plano de estruturação da pesquisa com as seguintes fazeres: Aquisição de informações existentes como: dados espaciais e temporais dos sites dos institutos do INPE, IBGE, e IEPA.

Apoio da imagem de satélite para definições de classes de uso e ocupações de solo.

As imagens utilizadas são do Landsat TM5, TM7 ETM+ e LandSat8 respectivamente dos anos 1991, 1995, 2006 e 2015. As composições das TM5 e TM7 ETM+ são coloridas Falsa-Cor/5r/4g/3b e Landsat8 as cores $6 \mathrm{r} / 5 \mathrm{~g} / 4 \mathrm{~b}$, tais quais possibilitou definir as classes de uso e ocupação do solo e vegetação, tendo como o recorte da área urbana do município de Ferreira Gomes.

Fase 2 - Geoprocessamento dos dados

Equivalente à geração e criação da base de dados digitais, permitindo (número) mapas classificatórios e de localização (mapas de uso e ocupação e vegetação). Para o mapeamento de uso e ocupação e cobertura vegetal foram utilizadas as fontes de dados das imagens Landsat na composição Falsa cor/5r/4g/3b e levantamentos em campo. Feito primeiramente interpretação da imagem em laboratório e posteriormente obteve-se levantamento de campo para confirmar as interpretações.

As classes processadas no software Ecognition para vetorização das de amostras foram: Vegetação, Solo exposto, Área Urbana e Vegetação Alterada. E pelo software Arcgis foi elaborado as técnicas de estéticas para o layout e correções de nuvens conhecido como método da classificação supervisionada MaxVer.

Fase 3 - Pós-Geoprocessamento

Equivalem as análises dos dados processados, alicerçadas ao diagnostico ambiental por geoprocessamento definido. Através das classes registradas desse mapa avaliativo poderão contribuir significadamente na elaboração ou atualização do plano diretor do referido município.

\section{Resultados e Discussão}

Com o uso de ferramentas de geoprocessamento foi possível apresentar em uma linha temporal a espacialidade em torno do município de Ferreira Gomes com dados para uma avaliação ambiental. Para essa avaliação foram definidos elementos que caracterizam fragmentos identificados em laboratório e campo, tais como Vegetação, Solo exposto, Área Urbana e Vegetação Alterada.

No ano de 1991 é possível verificar que a área de vegetação ocupava uma área de 8,44km², a área apresentava 0, $571 \mathrm{~km}^{2}$ e uma área de $2,729 \mathrm{~km}^{2}$ de vegetação alterada (Figura 2). Neste ano em 


\section{OS DESAFIOS DA GEOGRAFIA FÍSICA NA FRONTEIRA DO CONHECIMENTO \\ Instituto de Geociências - Unicamp \\ Campinas - SP \\ 28 de Junho à 02 de Julho de 2017}

quentão o município estava ocorrendo a construção da Ponte Tancredo Neves, que interliga a capital do estado e a própria cidade de Ferreira Gomes aos municípios da região norte do estado.

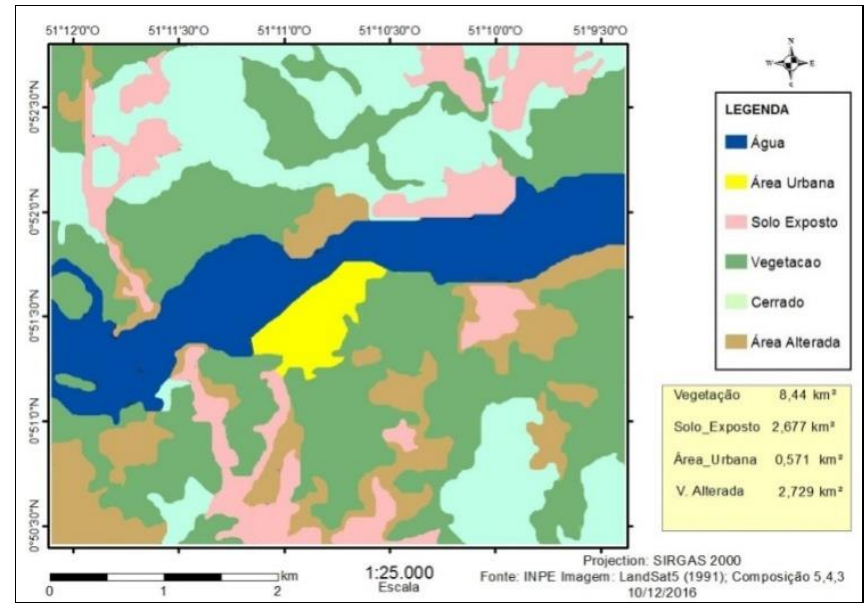

Figura 2 - Mapa de uso e ocupação da terra no ano 1991.

Em 2006 (figura 2), fez uma nova análise e comparou-se a mudanças do período decorrido de 15 anos, em que foi possível constata que a área de solos expostos teve um relativo aumento de $0.747 \mathrm{~km}^{2}$ assim 2016 o município apresentava uma área de $2,904 \mathrm{~km}^{2}$ de solo exposto. O destaque foi a expansão urbana que praticamente dobrou em relação ao ano de 1991 apresentando em 2006 uma área de $1.331 \mathrm{~km}^{2}$. A área de vegetação alterada que pouco mudou em relação às demais.

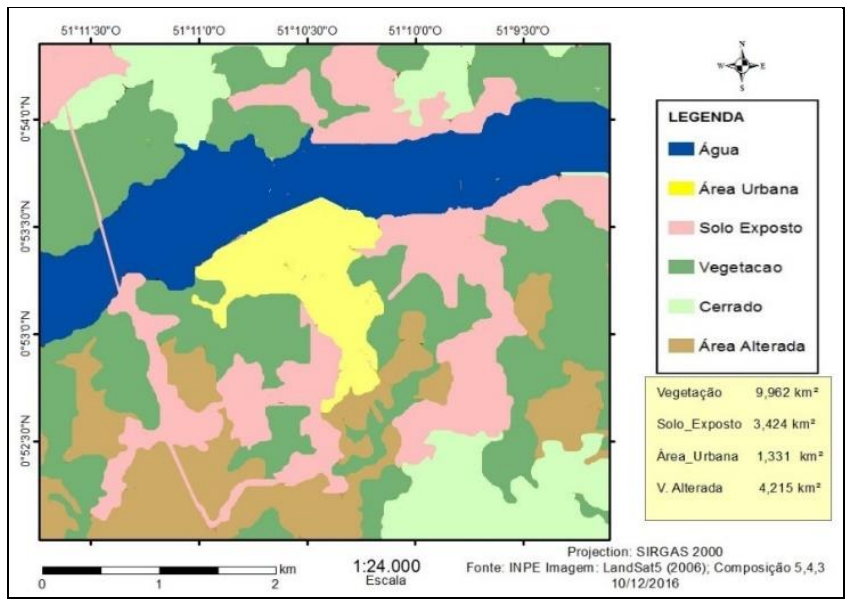

Figura 2 - Mapa de uso do solo de 2006.

Na Figura 3, em 2015 é notável em todos os itens de classificação o aumento da área urbana, onde aumentou para 1,699 $\mathrm{km}^{2}$ que praticamente triplicou devido à expansão urbana, que principalmente ocupava a margem do rio Araguari e teve sua expansão para as áreas mais altas, onde não ocorrem inundações devido as cheias do rio. A área alterada $7.475 \mathrm{~km}^{2}$ e solo exposto 10.766 mais que dobrou em relação à área apresentada no ano de 2006. Sendo possível verificar que as alterações no uso e ocupação da terra é progressiva no município, isso pode estar ligada a instalação da hidrelétrica Ferreira Gomes, construída bem próximo a cidade, que manteve todos os grupos de trabalhadores durante a construção da hidrelétrica. O empreendimento fez muitas alteração na paisagens do 


\section{OS DESAFIOS DA GEOGRAFIA FÍSICA NA FRONTEIRA DO CONHECIMENTO \\ Instituto de Geociências - Unicamp \\ Campinas - SP \\ 28 de Junho à 02 de Julho de 2017}

município com o desmatamento de floresta para os lagos e reservatórios da empresa bem como na dinâmica do rio, que passou a ser controlada de forma antrópica.

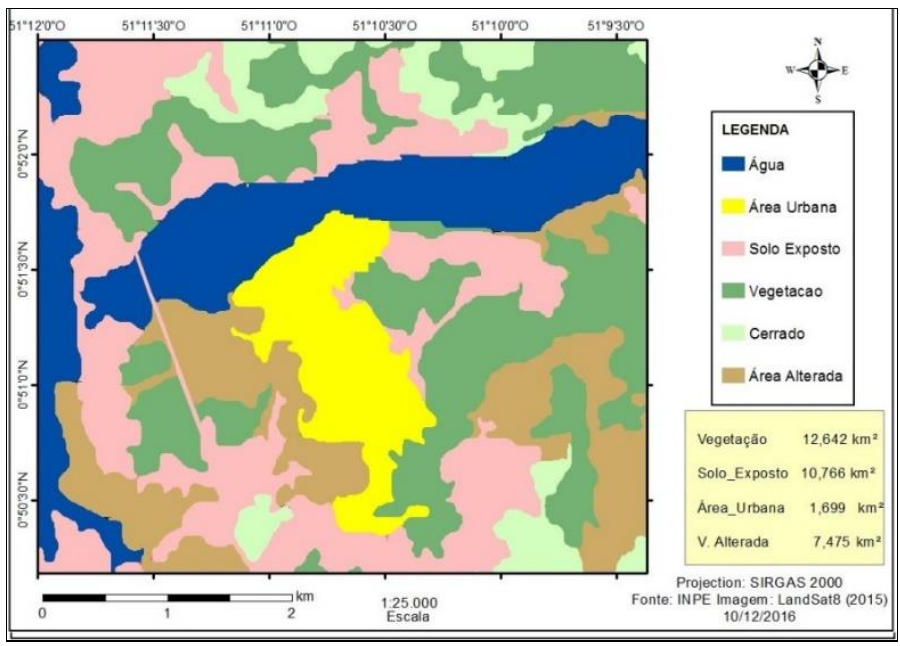

Figura 3 - Mapa de uso do solo de 2015.

\section{Considerações}

Pode-se verificar que durante os primeiros mapas que pouco era a área natural alterada no mesmo segmenta a área urbana de Ferreira Gomes. Mas em 2015 mais que dobrou essas áreas, haja vista que um marco importante e fator que ajudou possivelmente esses números foram os empreendimentos locais como as hidrelétricas, ao ser um chamativo de empregos para pessoas de outros municípios e estados.

Isso colaborou para o aumento da população local, consigo a demanda de novos espaços para moradias. Nessas áreas ao mesmo tempo de ocorrer um processo de expansão a alterações ambientais e que sem acompanhamento técnico-cientifico ficam vulneráveis a desastres ou moradias inapropriadas em lei e para saúde. Com o geoprocessamento e tecnologias, essas demandas para apoio de gestão territorial podem ser supridas. No que tange a sugestões para dar continuidade ao trabalho e sugerível uma avaliação a classificação dos índices por exatidão global, assim sendo, assim vai complementar de forma mais precisa os dados citados.

\section{Bibliografia}

Silva, J. Xavier da \& Zaidan, R. Tavares. Geoprocessamento e Analise Ambiental, 2004. Rio de Janeiro

IBGE. Cidades/ População Estimada 2015. Disponível em: http://cod.ibge.gov.br/4BJ acessado em: 08/03/2016 ás 14:16h.

Ponzoni, F. J. ; Shimabukuro, Y. E.; Kuplich, T. M. Sensoriamento Remoto da Vegetação. 2. ed. São Paulo: Oficina de Textos, 2012 